\title{
Standard Deviation of Thickness
}

National Cancer Institute

\section{Source}

National Cancer Institute. Standard Deviation of Thickness. NCI Thesaurus. Code C120722.

A measure of the range of values in a set of values that describe the thickness of an entity. 